\title{
PENGEMBANGAN VIDEO PEMBELAJARAN TARI: \\ Sebuah Alternatif Metode Belajar Tari
}

\author{
Kuswarsantyo, Kusnadi, Titik Agustin \\ Jurusan Pendidikan Seni Tari, FBS, Universitas Negeri Yogyakarta \\ E-mail: condrowaseso@gmail.com
}

\begin{abstract}
Abstrak
Pengembangan video pembelajaran tari ini bertujuan untuk memberikan kemudahan peserta didik yang akan mempelajari tari secara mendiri (tanpa guru). Video ini dibuat dengan dua sistem. Pertama dengan iringan lengkap, dan kedua tanpa iringan (hanya dengan hitungan). Cara penggunaan video pembelajaran tari ini adalah mengacu pada konsep pembelajaran SAS (Struktur Analisa Sintesa) yang merupakan metode keunsuran yang akan memberikan kejelasan pada peserta didik dalam mengamati ragam per ragam tari yang diajarkan. Metode ini dipadu dengan metode imitasi dan demonstasi yang dilakukan guru dalam media ini. Perpaduan metode pembelajaran tersebut untuk memperjelas aksentuasi gerak yang dilakukan model pada pengguna media ini (peserta didik/guru). Hasil dari pengembangan media pembelajaran melalui video ini adalah :1) peserta didik akan dimudahkan dalam menambah jam pelajaran di luar kelas ; 2) dengan media pembelajaran video ini tingkat kesalahan teknis mengenai ragam gerak dapat diminimalisir ; 3) dengan materi pembelajaran video ini akan meningkatkan kemampuan peserta didik dalam berkespresi baik gerak, irama dan penghayatan tarinya.
\end{abstract}

Kata kunci: pengembangan video, pembelajaran tari.

\section{THE DEVELOPMENT OF DANCE LEARNING VIDEO: An Alternative To The Dance Learning Method}

\begin{abstract}
The development of this dance learning video aims at making dance learning easy to do for independent learners. This video was made in two systems, first, with the complete music, and second, without the music (just by counting the tap). How to use this video is referred to the SAS learning concept, which is a kind of element method which explains how to observe each movement of the dance. This method is combined with the imitating and demonstrating methods conducted by the teacher in the video. The combination of these methods was conducted in order to make the movement clear. The results of the development of this learning media were: 1) the fact that it was easier for students to have extra time at schools; 2) the fact that the level of technical mistakes on the movement can be minimized by this learning media; and 3) the fact that through this video the students' ability can be improved in terms of expressing in movements, rhymes, and total comprehension.
\end{abstract}

Keywords: developing video, dance learning 


\section{PENDAHULUAN}

Idealnya belajar tari dapat dilakukan dengan mudah oleh siapapun yang ingin belajar. Terlepas dari apakah orang itu punya bakat atau tidak. Jenis tari apapun dapat dipelajari dengan cara yang mudah oleh siapapun, termasuk tari klasik gaya Yogyakarta. Akan tetapi kenyataan yang terjadi masih banyak siswa yang merasa kesulitan utnuk belajar tari klasik khususnya gaya Yogyakarta. Salah satu sebab dikarenakan pengajar tari masih menggunakan metode mengajar konvensional, yakni dengan cara imitasi dan drill. Cara ini masih banyak menemukan kendala, khususnya untuk mahasiswa dari luar Jawa. Berdasarkan hasil dialog dengan para mahasiswa luar Jawa yang belajar di Jurusan Pendidikan Seni Tari Universitas Negeri Yogyakarta, diketahui factor-faktor yang menyebabkan kesulitan belajar tari klasik gaya Yogyakarta ada tiga hal; 1) teknik gerak ; 2) penguasaan irama ; 3) penjiwaan tari.

Dalam tari klasik gaya Yogyakarta tiga penjiwaan tersebut merupakan aspek baku yang harus dipenuhi yang didasarkan pada jenjang tertentu secara proporsional. Oleh sebab itu diperlukan satu proses panjang yang disebut dengan latihan secara berkesinambungan. Oleh karena itu, perlu kiranya mencari media yang cocok untuk membantu mahasiswa / pelajar belajar tari. Ada dua media yang dapat dipandang sesuai dengan kebutuhan teknis, yakni video interaktif dan video pembelajaran non interaktif. Kedua bentuk media tersebut idealnya dapat dipadukan , karena pada hakekatnya kedua konsep media tersebut dapat saling mengisi dan mendukung.

Permasalahan yang muncul dengan adanya model penerapan media pembelajaran tersebut adalah bagaimana proses pengembangan dan bentuk produk video pembelajaran dasar-dasar tari gaya Yogyakarta yang terdiri dari dua bentuk repertoar yakni dasar putra dan putri yang memenuhi persyaratan validitas untuk meningkatkan efektivitas pembelajaran pada mata kuliah tari gaya Yogyakarta.

\section{MANFAAT MEDIA DALAM PEMEBALAJARAN TARI}

Praktik tari merupakan jenis pembelajaran keterampilan motorik. Menurut Gagne (dalam Wolfolk and Nicolisch), ada dua komponen penting dalam belajar keterampilan (motor skill) pertama petunjuk mengenai bagaimana gerakan itu dilakukan dan kedua adalah latihan gerak secara nyata dan kontinyu agar diperoleh gerakan yang baik. Dalam konteks pembelajaran praktik tari, hal tersebut biasa diistilahkan dengan pemahaman teknik dan 
latihan. Dalam hal ini media diperlukan untuk mempercepat pemahaman teknik tari dan memperlancar proses latihan agar lebih efektif dan efisien.

Pendapat para ahli pembelajaran menyatakan bahwa, media pembelajaran dapat meningkatkan kualitas proses pembelajaran. Beberapa diantaranya adalah Baugh (dalam Arsyad, 1996) yang menyatakan bahwa kurang lebih $90 \%$ hasil belajar seseorang diperoleh melalui indera pandang, dan $5 \%$ dari indera dengar dan $5 \%$ dari sumber lain. Sementara Dale (dalam Arsyad, 1996 memperkirakan $75 \%$ hasil belajar diperoleh melalui indera pandang, $13 \%$ dari indera dengar, dan lainnya $12 \%$. Dengan demikian pembelajaran tari seyogyanya tidak hanya mengandalkan metode ceramah yang mengeksploitasi indera pendengar, tetapi harus dikembangkan lebih lanjut variasinya terutama dengan menggunakan berbagai media yang relevan.

Berdasarkan perkembangn teknologi, media pembelajaran dapat dikelompokkan menjadi empat macam yaitu ; 1) media hasil teknologi cetak ;2) media hasil teknologi audio visual ; 3) media hasil teknologi yang berdasarkan komputer ; 4) media gabungan teknologi cetak dan komputer (Arsyad, $2009: 29$ )

Dalam pembelejaran praktik tari, media diperlukan dalam membantu mahasiswa/pelajar untuk memahami teknik gerak, serta memperlancar proses belajar mandiri di luar perkuliahan. Ada dua macam media yang relevan dipergunakan dalam pembelajaran praktik tari. Pertama media video interaktif dan kedua adalah video non interaktif. Masing masing media tersebut memiliki kelebihan dan kekurangan. Media interaktif efektif untuk pembelajaran yang sifatnya apresiatif, sedangkan video pembelajaran non interaktif efektif untuk pembelajaran praktik tari studio.

Pembelajaran praktik tari merupakan jenis belajar keterampilan motorik yang biasa dilakukan di studio. Oleh karena itu, media yang cocok untuk pembelajaran adalah media yang fleksibel dapat dipergunakan di tempat latihan. Dengan argumentasi tersebut video pembelejaran non interaktif dianggap lebih cocok.

\section{DASAR-DASAR TARI KLASIK GAYA YOGYAKARTA}

Tari Klasik Gaya Yogyakarta merupakan tarian yang bersifat abstrak dan simbolik, yang mengandung maksud seakan-akan permainan garis atau lijnenspel di dalam tari tidak ada artinya, akan tetapi di dalam stilering yang dilakukan terdapat simbolisasi dari karakter yang dikandung dalam ragam-ragam tari. Misalnya dalam ragam tari impur dan kambeng disimbolisasikan sifat-sifat yang tenang, tabah, dan sederhana, sementara itu, untuk putri ragam ngenceng merupakan simbolisasi keindahan dan kelembutan yang teguh. 
Pada dasarnya, seni tari klasik gaya Yogyakarta mempunyai dua sifat gerak, yaitu sifat gerak tari putri dan sifat gerak tari putra. Sifat gerak tari putra dibagi menjadi dua yang meliputi sifat tari putra alus dan sifat gerak tari putra gagah. Kedua sifat gerak tersebut berbeda-beda mengenai posisi sikap dan tekanan geraknya serta perasaan melakukannya harus sesuai dengan masing-masing sifat geraknya, namun mengenai paugeran-paugeran atau patokan-patokan geraknya sama.

Dalam belajar tari gaya Yogyakarta kita diperkenalkan dengan tiga unsur penguasaan, yang terdiri atas : wiraga, wirama dan wirasa. Wiraga berarti gerak dari seluruh anggota badan yang selaras. Artinya, untuk mempelajari tari gaya Yogyakarta pemahaman terhadap adanya patokan baku dalam hal gerak tertentu merupakan hal yang sangat penting. Gerakgerak yang termasuk dalam patokan baku meliputi : pandengan (arah pandangan mata ), pacak gulu (gerak leher), deg (sikap badan), cethik, mlumahing pupu (terbukanya posisi paha), nylekenthing (jari-jari kaki tegak ke atas), mendhak.

Semua gerak di atas merupakan gerak-gerak tersendiri. Akan tetapi, antara yang satu dengan yang lainnya saling berkaitan, sehingga akan tercipta sinkronisasi wiraga yang sempurna tatkala membawakan sebuah tarian tertentu. Wirama merupakan aspek tari yang selalu terkait dengan iringan. Iringan di dalam tari klasik gaya Yogyakarta berupa gamelan, lagon, kawin, ada-ada, suluk, dan kandha. Kedudukan antara tari dan karawitan saling mengikat satu sama lain dalam masing-masing fungsinya. Dalam kaitan ini tari Bedaya dan Srimpi dapat dijadikan contoh. Dalam tarian ini tampak jelas adanya ikatan yang kuat, yakni dalam hal tema dan geraknya yang mengikat diri pada karawitan. Demikian juga pada Beksan Lawung Gagah, naik turunnya irama gendhing yang mengiringi tari sesuai dengan naik turunnya irama gerak tari. Gerak tari menyesuaikan dengan bunyi kethuk, kenong, kempul, dan gong, sedang karawitan menyelaraskan diri dengan tema dan gerak tarinya.

Di samping apa yang telah dikemukakan di atas, dalam pelaksanaannya, tari hampir selalu diiringi oleh gendhing (iringan gamelan). Dalam kaitan inilah seorang atau sekelompok penari harus memiliki kepekaan terhadap irama. Kepekaan irama yang harus dikuasai oleh pembelajar tari ada tiga macam, yaitu

a. Kepekaan irama gendhing, yaitu ketajaman rasa untuk dapat mengikuti irama gendhing secara cermat dengan tekanan pada kethuk, kenong, kempul dan gong.

b. Kepekaan irama gerak, yaitu ketajaman rasa untuk dapat menggerakkan anggota tubuh dengan tempo ajeg atau tetap, sehingga menghasilkan gerak yang mengalir. 
c. Kepekaan irama jarak, yaitu ketajaman rasa dalam mengambil jarak antara anggota tubuh yang digerakkan. Jarak ini harus tetap, sesuai dengan kemungkinan keadaan anggota tubuh si penari dan menurut citarasa yang telah ditetapkannya sendiri. Misalnya, seberapa lebar jarak antara tumuit kaki kanan dan kiri pada waktu tancep dan sebagainya.

Dan yang terakhir adalah Wirasa. Seperti sudah dikemukakan oleh GBPH Suryobrongto (1976:90) dikatakan bahwa secara garis besar tari meliputi dua hal, yakni wadhah dan isi. Yang menjadi wadahnya adalah teknik tari, sedangkan yang menjadi isinya adalah Joged Mataram. Dalam kaitannya dengan tiga unsur yang sudah dikemukakan di atas, wirasa lebih dekat dengan Joged Mataram. Hal ini tersirat dalam teknik tariannya, yaitu greget (semangat) atau dinamika dalam inner (inner dynamic), sengguh (percaya diri atau self confidence) sawiji, memusat atau konsentrasi total, dan ora mingkuh, kemauan keras dan tidak ingkar janji.

Dengan prinsip greget, seorang penari diharuskan untuk menyalurkan atau mengekspresikan inner dynamic- nya melalui $\mathrm{d}$ an ke dalam gerak plastis dengan disertai pengendalian diri yang sempurna untuk menghindari over acting. Prinsip sengguh mengandung pengertian bahwa seorang penari harus tampil dengan penuh percaya diri pada kemampuannya (tetapi bukan dalam arti kesombongan). Ia harus mampu tampil menyatu dengan tari dan peran yang dibawakannya sebagai sebuah fenomena yang komplit.

Prinsip sawiji mengisyaratkan bahhwa penari harus melakukan konsentrasi total terhadap tari dan peran yang dibawakannya, bahkan lebih mengarah pada peleburan penuh antara diri si penari dengan tari yang dibawakan. Akhirnya, prinsip ora mingkuh , mewajibkan penari untuk melakukan kewajibannya dengan dedikasi dan loyalitas yang tinggi (Soedarsono, 1979/1980: 129).

Selanjutnya oleh Suryobrongto dijelaskan bahwa perwujudan Joged Mataram yang sudah terkristallisasi itu ada dua macam, yakni self-diciplin, yang artinya penguiasaan lahir dan batin, dan kepanjingan (ekstase). Dalam konsentrassi total, seorang penari akan mencapai tingkat kepancingan, yakni suatu tingkatan kerika perhatian seseorang penari hanya ditujukan pada apa yang terjadi di atas pentas. Meskipun demikian, jiwa raganya masih terkontrol penuh, karena konsentrasi tersebut tidak mengarah pada ketegangan jasmani atau rohani. Oleh karena itu, pembelajar tari gaya Yogyakarta harus mampu memahami serta menerapkan prinsip-prinsip keempat butir tersebut di atas. 
Terlebih lagi patokan baku yang ada pada tari gaya Yogyakarta secara rinci harus benar benar dipahami agar kualitas menarinya dapat maksimal. Patokan baku yang dimaksud dalam tari gaya Yogyakarta meliputi;Pandengan (arah pandangan mata ), Pacak Gulu (gerak leher) adalah gerak indah leher yang berpangkal pada gerak menekuk leher dan mendorong pangkal leher (jiling). Pada tari tari gaya Yogyakarta terdapat empat macam pacak gulu : (a) Pacak gulu baku; (b) tolehan, yang terdiri dari dua macam, yakni tolehan biasa dan nglengot; (c) Coklekan; (d) Gedheg. Kemudian Deg (Sikap badan ), yang merupakan sikap torso yang tegak lurus tanpa menegangkan pundak atau tulang belakang, tetapi juga tidak mengendorkannya. Sikap semacam ini akan membawa kita pada perasaan sumeleh atau mapan dengan tepat . Gerak Cethik (pangkal paha), gerak ini bermanfaat untuk keluweasan kaki dan lambung. Dengan demikian, gerakan ini berfungsi sebagai pengendali gerak-gerak yang berlebihan. Apabila gerak ini dilakukan dengan benar, tarian yang dibawakan akan terasa tenang dan stabil. Agar cethik dapat berfungsi dengan benar, paha juga harus berada pada posisi yang benar. Mlumahing Pupu ( terbukanya posisi paha ), posisi ini dimaksudkan agar gerak tari menjadi stabil, luwes, dan ringan. Apabila paha pada posisi yang benar, gerak yang dilakukan pun akan menjadi seimbang. Nyekenthing (jari-jari kaki tegak ke atas). Pada posisi ini kaki akan menjadi kokoh. Posisi nyekenthing ini akan mempengaruji intensitas semua gerakan dan sikap seluruh badan. Mendhak, posisi ini memungkinkan gerakan kaki lebih hidup, sehingga tarian tampak ebrah (besar). Mendhak ini dilakukan dengan memusatkan gerakan pada gerak cethik. Pada sisi yang lain, patokan yang tidak baku dimaksudkan sebagai kebebasan seorang penari dalam menafsirkan pola atau ragam tari yang ditentukan. Pertimbangannya ialah karena fisik penari yang satu dengan yang lain tidaklah sama. Oleh karenanya,berdasarkan pertimbangan itu, seorang penari boleh saja menyimpang dari patokan-patokan yang telah ditentukan sesuai dengan penafsiran dan selera si penari sendiri. Hanya, saja, penafsiran dan penyimpangan yang dilakukannya harus tetap mempertimbangkan sejumlah syarat, yaitu luwes, pantes, bersih dan cermat.

\section{PROSEDUR PENGEMBANGAN DESAIN PEMBELAJARAN}

Berdasakan kebutuhan dan tuntutan teknik menari yang dipersyaratkan dalam tari gaya Yogyakarta tersebut diperlukan adanya petunjuk mengenai bagaimana gerakan itu dapat dilakukan dan proses latihan yang terus menerus agar diperoleh gerakan yang baik. Untuk dapat membantu proses belajar tari tersebut diperlukan media untuk mengintensifkan fungsi tersebut. Ada dua media yang relevan dipergunakan untuk meningkatkan efektivitas dan efisiensi proses pembelajaran praktik dasar tari gaya Yogyakarta, yaitu dengan video 
interaktif dan non interaktif. Dengan pertimbangan fleksibilitas penggunaan dalam proses latihan, video pembelajaran non interaktif dianggap lebih tepat dipergunakan untuk jenis materi ekspresi tari, karena bisa dilakukan di tempat latihan dan dapat diputar dengan VCD/DVD maupun komputer atau laptop.

Pengembangan media pembelajaran dasar dasar tari klasik gaya Yogyakarta ini menggunakan model prosedural dengan delapan tahapan pokok yaitu : 1) analisis kebutuhan ; 2) perencanaan desain media ; 3) pengembangan produk awal ; 4) validasi ahli ; 5) Uji coba terbatas ; 6) revisi I ; 7) Uji coba lapangan ; 8) evaluasi akhir. Dengan melalui tahapan kegiatan tersebut diharapkan dapat memperoleh produk akhir media pembelajaran tari yang berkualitas sesuai dengan tujuan yang diharapkan.

Pada tahap analisis kebutuhan dan penelusuran konsep telah dilakukan pengamatan dengan melakukan wawancara dengan beberapa mahasiswa, terutama mereka yang mengalami kesulitan belajar tari gaya Yogyakarta.Berdasarkan hasil tersebut diketahui bahwa kesulitan utama terletak pada penguasaan tekbik gerak, penguasaan irama dan penjiwaan tari. Untuk itulah media pembelajaran ini akan menuntun mereka yang kesulitan untuk mempelajari tari gaya Yogyakarta.

Secara umum penyajian gerak tari dalam media ini dibagi menjadi dua bagian besar. Bagian pertama berisi penyajian ragam gerak per bagian dengan hitungan dari pengajar. Sedangkan bagian kedua berisi penyajian utuh dengan iringan. Secara detail bagian per bagian tersebut dapat dicontohkan dalam uraian dalam storyboard sebagai berikut.

\begin{tabular}{|c|c|}
\hline Visual & Audio \\
\hline \multicolumn{2}{|l|}{ Pembelajaran dasar tari gaya Yogyakarta } \\
\hline \multicolumn{2}{|l|}{ Pembelajaran Dasar tari Putri } \\
\hline Video dan teks hitungan & $\begin{array}{l}\text { Suara tutor putri } \\
\text { Dimulai dari sembahan sila, } \\
\text { jengkeng dari hitungan } 1-8\end{array}$ \\
\hline Video dan teks hitungan & Suara tutor putri \\
\hline & $\begin{array}{l}\text { Ragam nggurdha kiri mulai sesudah } \\
\text { hitungan delapan. Lima, enam tujuh } \\
\text { delapan. Terus } 1-8\end{array}$ \\
\hline Video dan teks hitungan & $\begin{array}{l}\text { Suara tutor putri } \\
\text { Ragam ongkek. Delapan. } \\
\text { Satu, dus, tiga, empat, lima, enam, } \\
\text { tujuh, delapan }\end{array}$ \\
\hline $\begin{array}{l}\text { Dan seterusnya hingga ragam } \\
\text { berakhir...... }\end{array}$ & $\begin{array}{l}\text { Dan seterusnya hingga ragam } \\
\text { berakhir...... }\end{array}$ \\
\hline
\end{tabular}


Contoh storyboard materi putra alus.

\begin{tabular}{|l|l|}
\hline \multicolumn{1}{|c|}{ Visual } & \multicolumn{1}{|c|}{ Audio } \\
\hline Pembelajaran dasar tari gaya Yogyakarta & \multicolumn{1}{|c|}{} \\
\hline Pembelajaran Dasar tari Putri & $\begin{array}{l}\text { Suara tutor putra } \\
\text { Mendhak ngoyog } \\
\text { Hitungan 7 -8. Satu - dua, tiga - } \\
\text { empat, lima - enam, tujuh-delapan. }\end{array}$ \\
\hline Video dan teks hitungan & Suara tutor putra \\
\hline Video dan teks hitungan & $\begin{array}{l}\text { Junjung tekuk kanan } \\
\text { TTujuh delapan. Satu-dua, tiga - } \\
\text { empat, lima- enam, tujuh- delapan. }\end{array}$ \\
\hline $\begin{array}{l}\text { Video dan teks hitungan } \\
\text { seterusnya hingga ragam } \\
\text { Derakhir...... }\end{array}$ & $\begin{array}{l}\text { Suara tutor putra } \\
\text { Sabetan nyamber kanan } \\
\text { Dan seterusnya hingga ragam } \\
\text { berakhir...... }\end{array}$ \\
\hline
\end{tabular}

Seterusnya kita bisa melakukan pencatatan tari sesuai dengan kebutuhan dan fokus pembelajaran yang disampaikan secara bersamaan dengan media audio visual yang telah terekam. Dengan cara ini siswa akan lebih efektif untuk melakukan kontrol terhadap teknik yang dilakukan model yang telah direkam dalam vedeo. Konsistensi model melalui media video ini tidak akan mungkin berubah karena sudah terekam dalam sistem teknologi, sehingga jika diulang ulang kualitas teknik peraga tetap konisten sepert yang telah ditentukan oleh patokan baku dalam teknik tari putri maupun putra..

Inilah salah satu cara atau model untuk memberikan pelajaran tari dengan memanfaatkan teknologi yakni melalui video interaktif maupun video non interaktif. Kelebihan dari model ini adalah setiap saat kelas tidak mungkin kosong, meski pengajar tidak bisa hadir mengaar. Karena modul dan media pembelajaran dapat dinerikan pengelola kelas untuk belajar mandiri. Dengan demikian efisiensi dan efektivitas pembelajaran akan tercapai tanpa mengurangi bobot pertemuan dengan guru secara langsung.

\section{KESIMPULAN}

Media pembelajaran apapun bentuknya akan sangat mendukung keberhasilan proses belajar peserta tepat akan didik. Dalam hal ini media pembelajaran adalah video (audio visual) yang memuat rincian gerak tari dengan metode Struktur Analisis Sintesis, yang secara rinci dapat diulang ulang oleh peserta didik. Keberadaan media pembelejaran berupa 
rekaman video dengan model yang secara kualitas memenuhi kriteria wiraga wirama dan wirasa yang baik akan memberikan kemudahan dalam menganalisa gerak per gerak, meskipun hanya melalui rekaman audio visual. Dengan media ini tingkat kesulitas peserta didik dalam mempelajari materi tari akan terminimalisir. Semoga media pembelajaran ini dapat dikembangkan menjadi media video interaktif yang akan lebih membuka komunikasiu antaramateri yang telah diprogram dengan pengguna (peserta didik) atau guru yang akan mempelajari tari.

\section{DAFTAR PUSTAKA}

Arsyad, Azhar, 2009. Media Pembelajaran. Jakarta : PT Raja Grafindo Persada Soedarsono, 1979. Pertumbuhan seni Pertunjukan Indonesia. Yogyakarta Akademi Seni Tari Indonesia.

Sugiyono, 2010. Metode Penelitian Kuantitatif Kualitatif dan $R \& D$. Bandung Alfabeta

Suryobrongto, 1976. Dasar dasar Tari Klasik gaya Yogyakarta. Yogyakarta Sekolah Menengah Karawita Indonesia.

Wolfolk, Anita and Nicolisch, Lorraine, 1984. Educational Phsycology fo Teacher. New Jersey Printece Hall Ince, Inglewood, Cliff. 